\title{
Pediatric patients' views regarding smoke-free hospital grounds compared to those of adults: A survey study
}

Leonieke J. Breunis', Maud Versteylen ${ }^{1,2}$, Márta K. Radón ${ }^{2,3}$, Nazmi Dereci',2, Nienke W. Boderie ${ }^{3}$, Marlou L. A. de Kroon ${ }^{1,4,5}$, Jasper V. Been $n^{1,2,3}$

\section{ABSTRACT}

INTRODUCTION Children are important stakeholders in discussions about regulation of smoking and protection from secondhand smoke, but are rarely acknowledged as such. We explored the opinion of pediatric patients and other key stakeholders regarding the planned smoke-free zone around the Erasmus MC, a large university hospital in the Netherlands.

METHODS In 2019, we conducted a survey among pediatric patients and their parents, Erasmus MC employees, visitors, and adult patients, before implementation of the outdoor smoke-free zone, to assess their opinions on smoking and the planned smoke-free policy. Qualitative and quantitative data were collected and analyzed mostly using descriptive statistics and thematic analysis.

RESULTS In all, 91 parent-child dyads and 563 employees, visitors, patients and students filled in the questionnaires. Over $90 \%$ of children reported that they were regularly exposed to tobacco smoke, most often on the streets. Many underlined the exemplary role of healthcare providers, and $89 \%$ felt that nobody should be allowed to smoke near the hospital. Among parents, 89\% were (very) positive towards the planned implementation of the smoke-free zone. In addition, $70 \%$ of adult patients, $81 \%$ of employees, $65 \%$ of visitors, $89 \%$ of students and $75 \%$ of 'others' were (very) positive about the new smoke-free policy. Smokers and former smokers generally were less positive about the policy.

CONCLUSIONS Children generally disapproved smoking around a hospital and felt that healthcare providers should be a good example concerning not smoking. The majority of adult patients, employees and visitors support a smoke-free zone surrounding the hospital, and virtually all pediatric patients and their parents do. Children should be acknowledged as important stakeholders in smoke-free policies and should be involved in planning and implementation.

\begin{abstract}
AFFILIATION
1 Department of Obstetrics and Gynaecology, Division of Obstetrics and Foetal Medicine, Erasmus MC Sophia Children's Hospital, Erasmus University Medical Center, Rotterdam, The Netherlands

2 Department of Paediatrics, Division of Neonatology, Erasmus MC Sophia Children's Hospital, Erasmus University Medical Center, Rotterdam, The Netherlands

3 Department of Public Health, Erasmus University Medical Center, Rotterdam, The Netherlands

4 Department of Health Sciences, University of Groningen Medical Centre, Groningen, The Netherlands 5 Department of Public Health and Primary Care, Environment and Health, KU Leuven, Leuven, Belgium

CORRESPONDENCE TO

Jasper V. Been. Department of Obstetrics and Gynaecology, Division of Obstetrics and Foetal Medicine, Erasmus MC Sophia Children's Hospital, Erasmus University Medical Center, Wytemaweg 80, 3015 CN, Rotterdam, The Netherlands. E-mail: j.been@ erasmusmc.nI ORCID ID: https://orcid. org/0000-0002-4907-6466
\end{abstract}

\section{KEYWORDS}

smoking, attitude, child, smoke-free policy, parents, hospitals

Received: 4 October 2021

Revised: 21 December 2021

Accepted: 22 December 2021

\section{INTRODUCTION}

Tobacco use, including secondhand smoke (SHS) exposure, is the leading cause of preventable premature death globally ${ }^{1}$. Worldwide almost half of children are regularly exposed to SHS and two- thirds of smokers started smoking before the age of 18 years ${ }^{1,2}$. Hence, children are important stakeholders in discussions about regulation of smoking and protection from SHS. However, they are rarely acknowledged as such ${ }^{3}$. 
Outdoor smoke-free zones are increasingly implemented to protect people from SHS exposure, to support smoking cessation, and to help denormalize smoking ${ }^{4}$. In the Netherlands, as of August 2020 educational institutions (including university medical centers) are legally required to ensure that their grounds are smoke-free ${ }^{5}$. In anticipation of this regulation, the Erasmus MC, including the Sophia Children's Hospital, in collaboration with a neighboring high school and the Rotterdam University of Applied Sciences, implemented the first inner-city voluntary smokefree zone in Rotterdam in September $2019^{6}$. As part of preparatory actions, we explored the opinion of key stakeholders regarding the planned smoke-free hospital grounds. Because many vulnerable children visit the Sophia Children's Hospital, we included pediatric patients and their parents in our study. In this article, we report the opinions of all stakeholders with particular focus on those of pediatric patients and their parents.

\section{METHODS}

\section{Design}

In this cross-sectional study with a mixed methods approach, we surveyed patients, employees and visitors of Erasmus MC to explore their opinion about the planned smoke-free zone. One survey particularly focused on pediatric patients of the Sophia Children's Hospital and their parents. We extracted both qualitative and quantitative data from the questionnaires.

\section{Setting and participants}

From March till April 2019, we approached inpatient and outpatient children aged 4-16 years of the Sophia Children's Hospital and their parents/caregivers for participation. Pediatric outpatients and their parents were non-selectively approached in hospital waiting areas. Children and parents were excluded if they were unable to answer questions verbally or in writing. Following consent, the questionnaire was immediately filled in. Participating children received a small toy present. We aimed for a convenience sample of 100 parent-child dyads. From February till July 2019, we handed out questionnaires to adults passing through the main hallway of the hospital or visiting outpatient clinics.

\section{Data collection}

We developed separate questionnaires for primary school children, high school children, and parents/ caregivers. The pediatric questionnaires consisted of thirty questions about personal characteristics, and their opinion regarding smoking, SHS, thirdhand smoke (THS; the chemical residue of tobacco smoke lingering after the cigarette is extinguished ${ }^{7}$ ), parents and healthcare providers who smoke, and a smokefree zone surrounding hospitals. The parental questionnaire consisted of 27 questions about personal characteristics, their knowledge regarding smoking, SHS and THS, and their opinion about a smoke-free zone around the hospital. Furthermore, we assessed whether parents felt that their child's opinion influenced their smoking behavior.

For questions assessing opinions and beliefs, a fivepoint Likert scale (very negative to very positive) was used. For primary school children, the fivepoint Likert scale was converted to emojis. Before conducting the survey study, the questionnaire was tested with several young children and adapted when needed to enhance comprehensibility. In an attempt to minimize parental influence on their child's responses and vice versa, parents and children filled in the questionnaires separately. Moreover, if children were unable to read or write, one researcher read the questions to the child and filled in the exact answer given by the child. Parents did not help to answer questions.

The questionnaire for adult patients, employees and visitors consisted of 21 questions related to smoking and a smoke-free policy. In this study, we report on participants' knowledge on health effects of smoking, and opinion regarding the smoke-free zone.

\section{Data analysis}

Descriptive statistics were used to describe the population and their responses. We assessed whether smoking status of the adults (non-smoker/former smoker/current smoker) was associated with their opinion about the smoke-free zone, via ordinal regression adjusted for age and sex. Open-ended questions were analyzed using thematic analysis.

\section{RESULTS}

\section{Study population}

Ninety-two parent-child dyads filled in the 
questionnaire. One parent-child dyad was excluded because the child was aged above 16 years; $52 \%$ of participating children were primary school children, $56 \%$ were female and $90 \%$ were outpatient (Supplementary file Table 1). None of the primary school children and $14 \%$ of high school children had ever smoked. Over $90 \%$ of children reported that they experienced SHS exposure regularly, with most reporting smoke exposure on the streets. Most parents were never-smokers, $24 \%$ were former smokers and $15 \%$ were current smokers. Of the smoking parents, $14 \%$ never smoked near their child and $43 \%$ said they would quit smoking if they believed their child was bothered by it.
Opinions on a smoke-free hospital

Opinions were obtained based on the question: 'What do you think when you see a doctor smoking?':

'You are here to cure people, then you cannot smoke.' (girl, 9 years)

'Bad for the children she [the doctor] treats.' (boy, 9 years)

'I think I do not want that doctor then.' (girl, 14 years)

'He [the doctor] does tell me I shouldn't smoke, but he does so [smoking] himself.' (girl, 12 years)

Among the children, $89 \%$ said that nobody should be allowed to smoke around the hospital and many children underlined the exemplary role of healthcare

Table 1. Opinions of pediatric patients concerning a smoke-free hospital ${ }^{a}$

\begin{tabular}{|c|c|c|c|c|}
\hline Questions & Yes & No & Don’t know & Missing \\
\hline Should anyone be allowed to smoke around the hospital? & $3(3)$ & $81(89)$ & $6(7)$ & $1(1)$ \\
\hline Should doctors be allowed to smoke around the hospital? & $3(3)$ & $82(90)$ & $5(6)$ & $1(1)$ \\
\hline Should doctors be allowed to smoke at home? & $58(64)$ & $18(20)$ & $14(15)$ & $1(1)$ \\
\hline Should nurses be allowed to smoke around the hospital? & $4(4)$ & $79(87)$ & 7 (8) & $1(1)$ \\
\hline Should nurses be allowed to smoke at home? & $57(63)$ & $18(20)$ & $15(17)$ & $1(1)$ \\
\hline
\end{tabular}

a Data presented as $n(\%)$.

Table 2. Opinions of adults concerning a smoke-free hospital ${ }^{a}$

\begin{tabular}{|c|c|c|c|c|c|c|}
\hline Category & Never & Rarely & Sometimes & Often & Always & Missing \\
\hline Parent $(n=91)$ & $18(20)$ & $28(31)$ & $30(33)$ & $6(7)$ & $9(10)$ & $0(0)$ \\
\hline Patient $(n=168)$ & $43(26)$ & $34(20)$ & $42(25)$ & $18(11)$ & $28(17)$ & $3(2)$ \\
\hline Employee $(n=191)$ & $16(8)$ & $28(15)$ & $58(30)$ & $46(24)$ & $41(22)$ & $2(1)$ \\
\hline Visitor $(n=133)$ & $39(29)$ & $35(26)$ & $27(20)$ & $17(13)$ & $14(11)$ & $1(1)$ \\
\hline Student $(n=35)$ & $3(9)$ & $6(17)$ & $8(22)$ & $5(14)$ & 7 (19) & $1(3)$ \\
\hline Other $(n=36)$ & $10(28)$ & $5(14)$ & $8(22)$ & $5(14)$ & 7 (19) & $1(3)$ \\
\hline Total $(n=654)$ & $129(20)$ & $136(21)$ & $173(26)$ & $97(15)$ & 106 (16) & $8(1)$ \\
\hline \multicolumn{7}{|c|}{ How do you feel about a completely smoke-free zone surrounding the hospital? } \\
\hline Category & Very negative & Negative & Neutral & Positive & Very positive & Missing \\
\hline Parent $(n=91)$ & $0(0)$ & $1(1)$ & $9(10)$ & $18(20)$ & $63(69)$ & $0(0)$ \\
\hline Patient $(n=168)$ & $6(4)$ & $21(13)$ & $21(13)$ & $40(24)$ & $77(46)$ & $3(2)$ \\
\hline Employee $(n=191)$ & $5(3)$ & $14(7)$ & $15(8)$ & $29(15)$ & $126(66)$ & $2(1)$ \\
\hline Visitor $(n=133)$ & $6(5)$ & $15(11)$ & $23(17)$ & $30(23)$ & $57(43)$ & $2(2)$ \\
\hline Student $(n=35)$ & $0(0)$ & $2(6)$ & $2(6)$ & $8(23)$ & $23(66)$ & $0(0)$ \\
\hline Other $(n=36)$ & $1(3)$ & $1(3)$ & $6(17)$ & $6(17)$ & 21 (58) & $1(3)$ \\
\hline Total $(n=654)$ & $18(3)$ & $54(8)$ & 76 (12) & 131 (20) & 367 (56) & $8(1)$ \\
\hline
\end{tabular}

a Data presented as n (\%). 
providers in this regard; $90 \%$ of the children felt that a medical doctor should not smoke around the hospital, while $64 \%$ agreed they should be allowed to smoke at home, for nurses this was $87 \%$ and $63 \%$, respectively (Table 1 ). Of the parents, $49 \%$ were sometimes, often or always bothered by smokers near the entrance of the hospital, and $89 \%$ were (very) positive towards the planned implementation of the smoke-free zone (Table 2).

The questionnaire for adults was filled in by 168 patients, 191 employees, 133 visitors, 35 students, and 36 others (e.g. interpreter, taxi driver); 86\% of respondents were sometimes, often or always bothered by smoking near the hospital (Table 2); $70 \%$ of patients, $81 \%$ of employees, $65 \%$ of visitors, $89 \%$ of students and $75 \%$ of 'others' were (very) positive about the planned smoke-free policy (Table 2 ). Former smokers and current smokers were less likely to support the smoke-free zone $(\mathrm{OR}=0.547$; 95\% CI: $0.361-0.828$ and OR=0.074; 95\% CI: $0.044-$ 0.123 , respectively).

\section{Opinions on smoking}

Opinions were obtained based on the question: 'What is smoking?':

'During smoking, smoke comes out of your mouth which is very bad for your health.' (girl, 8 years)

'That is bad stuff and that can make you really sick.' (girl, 10 years)

'You inhale something that smells.' (girl, 7 years)

'A little pipe with all kinds of bad stuff in it.' (boy, 9 years)

While many children indicated that smoking and SHS are unhealthy (96\% and $81 \%$, respectively), only $23 \%$ believed that THS is bad for their health. Similarly, among parents more than 95\% (strongly) agreed that smoking and SHS are unhealthy, while only $21 \%$ (strongly) agreed THS is unhealthy. For adults, this was $92 \%, 91 \%$, and $46 \%$, respectively. Of the children, $93 \%$ felt that smoking was not cool at all and $90 \%$ disapproved of smoking by peers.

\section{DISCUSSION}

In this study, the vast majority of pediatric patients and their parents supported smoke-free hospital grounds, including most smoking parents and their children. Surveyed children were aware that smoking and SHS are bad for their health, regularly experience smoke exposure, and felt that healthcare providers have an exemplary role not to smoke. Adult patients, visitors, and particularly employees and students, who spend most time around the hospital, were often bothered by smoking in the area. Almost three-quarters of adult patients, employees, visitors, and students supported smoke-free hospital areas, providing grounds for implementation of smoke-free zones surrounding hospitals.

To our knowledge, our study is the first to have evaluated children's opinions regarding outdoor smoke-free policies around hospitals. This is important as children are important stakeholders in the discussion around implementation of smokefree areas. Answers to the open questions provide a unique insight and can provide motivation for smokers to quit smoking at places children visit.

The Global Youth Tobacco Survey, conducted in 115 countries in 2000-2006, showed that the majority of children aged 13-15 years supported smoke-free policies in indoor public places ${ }^{8}$. A survey among youth aged 11-18 years from North Carolina showed that in 2009, 63\% of middle school and 54\% of high school children supported completely smoke-free outdoor public places ${ }^{9}$. More recent surveys and group interviews among Dutch adolescents (predominantly aged 15-16 years) showed that they have mixed support for outdoor smoke-free zones, partly based on the impression that individuals have a 'right to smoke'10. In our study, we also included younger children and focused particularly on hospital areas, which might explain the considerably larger level of support in our study. According to $69 \%$ of Dutch adults surveyed in 2019, more smoke-free areas should be implemented, especially in places often visited by children ${ }^{3}$. We are unaware of any previous studies having assessed children's or healthcare professionals' opinions on smoking near hospitals. A previous survey study concerning smoking among Croatian healthcare providers showed that $75 \%$ (strongly) agreed to being an example to their patients, and $68 \%$ (strongly) agreed to being an example to society in general ${ }^{11}$. Most children in our study had a negative attitude towards smoking by healthcare providers and underlined that healthcare providers have an exemplary role.

Our study shows that the vast majority of pediatric 
patients and their parents support a smoke-free hospital, even more so than adult patients, employees and visitors of the hospital. Although many measures to prevent children from initiating smoking and to protect them against SHS exposure are being implemented, the prevalence of SHS exposure in outdoor public places remains high ${ }^{12}$. Children represent the next generation, and their opinions need to be considered when designing smoke-free policies. They can be actively involved in designing policies and communication approaches for example via co-creation sessions in schools. Furthermore, children's attitudes could serve as motivator for smokers to comply with smoke-free policies or to quit smoking. For example, earlier work showed that broadcasting children's opinions near hospital entrances helped reduce smoking in these places ${ }^{13}$. Although the vast majority of smoking parents in our study smoked near their children, half of them said they would quit smoking if their child was bothered by it.

Additional studies in other geographical areas are needed to substantiate our findings, and should assess children's opinions on smoke-free outdoor policies in other places frequented by children.

\section{Limitations}

Limitations of the study include the relatively small sample size and the single-center approach. Our inclusion of primarily outpatients limits the generalizability to hospitalized children. Because we conducted our research in a tertiary medical center, many hospitalized children were too sick or mentally affected by their illness to fill in the questionnaire. We had planned to assess which factors were associated with support for a smoke-free hospital, but due to the low number of children not supporting a smokefree hospital, these analyses could not be performed. Moreover, selection bias could have occurred because parents and children having strong feelings about smoking may have been more willing to participate. Due to the setting in which the survey was conducted (i.e. in the hospital) social desirability bias could have occurred.

\section{CONCLUSIONS}

Smoke-free hospital grounds are supported by the vast majority of pediatric patients as well as their parents and other stakeholders. Children should be acknowledged as important stakeholders in discussions about smoke-free policies and be involved in decision-making when considering implementing novel policies, particularly in places frequented by children.

\section{REFERENCES}

1. World Health Organization. Tobacco. July 26, 2020. Accessed February 20, 2021. http://www.who.int/en/ news-room/fact-sheets/detail/tobacco

2. U. S. Department of Health and Human Services. The Health Consequences of Smoking-50 Years of Progress. A Report of the Surgeon General. U. S. Department of Health and Human Services, Centers for Disease Control and Prevention, National Center for Chronic Disease Prevention and Health Promotion, Office on Smoking and Health; 2014. PMID: 24455788.

3. Rookvrije generatie, Hartstichting, KWF kankerbestrijding, Longfonds. Infographic: Driekwart Nederlanders pleit voor actief rookvrij beleid. 2019. Accessed February 20, 2021. http://rookvrijegeneratie. nl/wp-content/uploads/2019/05/KWF025_infographic_ ANR_DEF.pdf

4. Martínez C, Guydish J, Robinson G, Martínez-Sánchez JM, Fernández E. Assessment of the smoke-free outdoor regulation in the WHO European Region. Prev Med. 2014;64:37-40. doi:10.1016/j.ypmed.2014.03.020

5. Government of the Netherlands. The National Prevention Agreement. Nationaal Preventieakkoord. Ministerie van Volksgezondheid, Welzijn en Sport; 2018. Accessed February 20, 2021. https://www.government. nl/documents/reports/2019/06/30/the-nationalprevention-agreement

6. Breunis LJ, Bebek M, Dereci N, de Kroon MLA, Radó MK, Been JV. Impact of an inner-city smoke-free zone on outdoor smoking patterns: a before-after study. Nicotine Tob Res. 2021;23(12):2075-2083. doi:10.1093/ntr/ ntab109

7. Ferrante G, Simoni M, Cibella F, et al. Third-hand smoke exposure and health hazards in children. Monaldi Arch Chest Dis. 2013;79(1):38-43. doi:10.4081/monaldi.2013.108

8. Koh HK, Alpert HR, Judge CM, et al. Understanding worldwide youth attitudes towards smoke-free policies: an analysis of the Global Youth Tobacco Survey. Tob Control. 2011;20(3):219-225. doi:10.1136/tc.2010.038885

9. Kandra KL, McCullough A, Ranney L, Goldstein AO. Support among middle school and high school students for smoke-free policies, North Carolina, 2009. Prev Chronic Dis. 2012;10:120135. doi:10.5888/pcd10.120135

10. Schreuders M, Lagerweij NA, van den Putte B, Kunst AE. To what extent and why adolescents do or do not support future tobacco control measures: a multimethod study in the Netherlands. Tob Control. 2018;27(5):596-599. 
doi:10.1136/tobaccocontrol-2017-053770

11. Juranić B, Rakošec Ž, Jakab J, Mikšić Š, Vuletić S, Ivandić M, Blažević I. Prevalence, habits and personal attitudes towards smoking among health care professionals. J Occup Med Toxicol. 2017;12:20. doi:10.1186/s12995-017-0166-5

12. The TackSHS Project Investigators, Henderson E, Lugo A, Liu X, Continente X, Fernández E, López MJ. Secondhand smoke presence in outdoor areas in 12 European countries. Environ Res. 2021;110806. doi:10.1016/j.envres.2021.110806

13. Webb A, Tascone B, Wickham L, et al. Hospital entrance smoking is reduced by broadcasting recorded antitobacco messages from Australian primary school children over entrance public address system. Health Promot J Austr. 2021;32(Suppl 2):351-357. doi:10.1002/hpja.435

\section{ACKNOWLEDGEMENTS}

The authors thank all participants in this research.

\section{CONFLICTS OF INTEREST}

The authors have completed and submitted the ICMJE Form for Disclosure of Potential Conflicts of Interest and none was reported.

\section{FUNDING}

This research was funded by a joint project grant from the Dutch Heart Foundation, Lung Foundation Netherlands, Dutch Cancer Society, Dutch Diabetes Research Foundation and the Netherlands Thrombosis Foundation (Grant number: 2.1.19.010). The presents for children filling in the questionnaires were provided by the Friends of Sophia Foundation (in Dutch: Vrienden van Sophia). The funders had no role in the writing of the manuscript or in the decision to submit the article for publication.

\section{ETHICAL APPROVAL AND INFORMED CONSENT}

The study was reviewed by the Medical Ethics Committee of the Erasmus $\mathrm{MC}$ and it was declared that the rules of the Medical Research Involving Human Subjects Act (in Dutch: WMO) did not apply to this study (MEC2019-0100 and MEC-2019-0012). Participants, and parents of participants when applicable, provided oral consent for participation.

\section{DATA AVAILABILITY}

The data supporting this research are available from the authors on reasonable request.

\section{AUTHORS' CONTRIBUTIONS}

UB obtained funding for the presents, developed the questionnaires, supervised the research, performed the statistical analyses, and drafted the manuscript. MV developed and conducted the pediatric and parental questionnaires, performed the statistical analyses and drafted the manuscript. MKR performed the statistical analyses. ND and NWB developed and conducted questionnaires for patients, employees and visitors. MLAdK supervised the research. JVB obtained funding for the study, supervised the research and drafting of the manuscript. All authors were involved in interpretation of the findings, performed critical revisions of the manuscript and read and approved the final manuscript.

PROVENANCE AND PEER REVIEW

Not commissioned; externally peer reviewed. 